\title{
Understanding the Chinese stock market: international comparison and policy implications
}

Article

Accepted Version

Liu, Z. and Wang, S. (2017) Understanding the Chinese stock market: international comparison and policy implications. Economic and Political Studies, 5 (4). pp. 441-455. ISSN 2095-4816 doi:

https://doi.org/10.1080/20954816.2017.1384616 Available at https://centaur.reading.ac.uk/79667/

It is advisable to refer to the publisher's version if you intend to cite from the work. See Guidance on citing.

To link to this article DOI: http://dx.doi.org/10.1080/20954816.2017.1384616

Publisher: Taylor \& Francis

All outputs in CentAUR are protected by Intellectual Property Rights law, including copyright law. Copyright and IPR is retained by the creators or other copyright holders. Terms and conditions for use of this material are defined in the End User Agreement.

www.reading.ac.uk/centaur 
Central Archive at the University of Reading

Reading's research outputs online 


\title{
Understanding the Chinese stock market: international comparison and policy implications
}

\author{
Zhenya Liu ${ }^{a, b}$ and Shixuan Wang ${ }^{b, c}$ \\ ${ }^{a}$ China Financial Policy Research Center, School of Finance, Renmin University of China, Beijing, \\ China; ${ }^{b}$ Department of Economics, University of Birmingham, Birmingham, UK; ${ }^{\mathrm{C} C a r d i f f}$ Business \\ School, Cardiff University, Cardiff, UK
}

\begin{abstract}
The definitions of the bear, sidewalk and bull markets are ambiguous in the existing literature. This makes it difficult for practitioners to distinguish between different market conditions. In this paper, we propose statistical definitions of the bear, sidewalk and bull markets, which correspond to the three states in our hidden semi-Markov model. We apply this analysis to the daily returns of the Chinese stock market and seven developed markets. Using the Viterbi algorithm to globally decode the most likely sequence of the market conditions, we systematically find the precise timing of the bear, sidewalk and bull markets for all the eight markets. Through the comparison of the estimation and decoding results, many unique characteristics of the Chinese stock market are revealed, such as 'crazy bull', 'frequent and quick bear' and 'no buffer zone'. In China, the bull market is more volatile than in developed markets, the bear market occurs more frequently than in developed markets, and the sidewalk market has not functioned as a buffer zone since 2005. Possible causes of these unique characteristics are also discussed and implications for policy-making are suggested.
\end{abstract}

\section{ARTICLE HISTORY}

Received 24 December 2015

Accepted 18 April 2016

Published online

\section{KEYWORDS}

Chinese stock market; asset return; hidden semi-Markov model; market conditions; policy implications

\section{Introduction}

The rules and structures of the Chinese stock market are considerably different from those of developed stock markets. Firstly, the Chinese stock market is heavily influenced by policy, rather than being market-orientated. The Chinese government is extensively involved in the stock market and has imposed a number of special restrictions. Secondly, the Chinese stock market consists mainly of individual investors, whereas institutional investors dominate in developed markets. Thirdly, the Chinese stock market is still under development and lacks financial derivatives to manage risk. For example, index futures and options trading in China is subject to a number of restrictions, which makes them inaccessible for the majority of investors. It is worthwhile investigating the distinctive characteristics of the Chinese stock market. 
It is natural to ask how these different rules and structures might affect the market behaviour. Many studies have investigated the Chinese stock market from different perspectives. Herding behaviour, overreaction and speculation in the Chinese stock market are well-documented. Tan et al. (2008) study the herding behaviour in the Chinese stock market, including both A-share and B-share. They find that herding happens in both upside and downside market conditions. Particularly, the herding behaviour is stronger in upside market conditions in A-share. Investor sentiment and its nonlinear effect on stock returns in China are studied by $\mathrm{Ni}$, Wang, and Xue (2015) through the panel quantile regression model. The nonlinear effect of investor sentiment turns out to be asymmetric and reversal, which proves the occurrence of overreaction in the Chinese stock market. In addition, they observe that Chinese investors are affected by cognitive bias and speculation tendencies. In the literature, however, very few works have studied the market behaviour from the perspective of market conditions. To the best of our knowledge, the difference of the market conditions between the Chinese stock market and developed markets is seldom addressed, especially after 2005 .

Market conditions have been studied mostly with Markov-switching techniques. Schaller and Van Norden (1997) consider a two-regime model which allows the mean and/or the variance of returns to vary in different regimes for the US stock market. Nielsen and Olesen (2001) find that a third regime, the speculative market, exists in some European markets. Girardin and Liu (2003) adopt a switch-in-the-mean plus switch-in-the-variance (MSMH(3)-AR(5)) model for weekly capital gains on the Shanghai A-share market during the period between 1995 and 2002. They also find that there are three market conditions: a speculative market, a bull market and a bear market. They claim that the bull market is always a buffer zone in the transition between the other two market conditions. It should be noted that the buffer zone defined in the research of Girardin and Liu (2003) is the bull market, while the sidewalk market is regarded as the buffer zone in this paper.

The hidden Markov model (HMM) and hidden semi-Markov model (HSMM) used in financial studies focus on the reproduction of stylised facts of daily returns. Rydén, Teräsvirta, and Åsbrink (1998) firstly adopt a two-state HMM with normal distributions (zero mean but different variance) as the component distribution (a.k.a. marginal distribution) to reproduce most of the stylised facts of daily returns, except for the slow decay in the autocorrelation function of squared returns. Bulla and Bulla (2006) use a two-state HSMM, which is a generalisation of HMM, to model daily returns of $18 \mathrm{US}$ sector indexes. The stylised facts of daily returns are reproduced by HSMM, including the long memory in the autocorrelation function of squared returns. Liu and Wang (2017) use a three-state HSMM on the daily returns of CSI 300 and show that the stylised facts of daily returns in China also can be reproduced. Their empirical results suggest that three-state HSMM is appropriate for the CSI 300, and it is better than two-state HSMM, three-state HMM, two-state HMM and GARCH(1,1) model. In this paper, we follow Liu and Wang (2017) to employ the three-state HSMM to systematically find the precise timing of the bear, sidewalk and bull markets.

This paper aims to statistically identify the unique characteristics of the market conditions in the Chinese stock market through international comparison. 
The definitions of the bear, sidewalk and bull markets are very vague in the existing literature, making it difficult for practitioners to distinguish between stock markets in different market conditions. In this paper, we propose statistical definitions of the bear, sidewalk and bull markets, which correspond to the states in our three-state HSMM. We apply this analysis to the daily returns of the Chinese stock market and seven developed markets. Using the Viterbi algorithm (Viterbi 1967) to globally decode the most likely sequence of the market conditions, we systematically find the precise timing of the bear, sidewalk and bull markets for all the eight markets. Through the comparison of the estimation and decoding results, several unique characteristics of the Chinese stock market are found, such as 'crazy bull', 'frequent and quick bear' and 'no buffer zone'. 'Crazy bull' refers to a considerably high variance in the bull market. 'Frequent and quick bear' means that the bear market has a short sojourn time and occurs very frequently. 'No buffer zone' describes that the bull market is typically mixed with the bear market and there is no sidewalk market between them.

The remainder of the paper is structured as follows. This paper first reviews the key differences between the Chinese stock market and developed markets. In the methodology part, the statistical definitions of the bear, sidewalk and bull markets are proposed. We then introduce the HSMM that we will subsequently use. In the empirical results part, the unique characteristics of the Chinese stock market are identified by comparing estimation and decoding results with developed markets. Finally, the possible causes of the unique characteristics are discussed and several policy implications are suggested.

\section{Review of the Chinese stock market}

The Chinese stock market is heavily influenced by policies, rather than being marketoriented. The Chinese government is considerably involved in the stock market and intervenes frequently. Policies on the Chinese stock market are unstable. For example, in addition to price limits, the China Securities Regulatory Commission (CSRC) imposed 'Circuit Breaker' on 1 January 2016. In China, the 'Circuit Breaker' mechanism depends on the abnormal movement of the market index (CSI 300). Specifically, the trading of stocks and relevant derivatives will be suspended for 15 minutes if the market index rises/drops $5 \%$, and the trading will be stopped for the rest of the day if the market index rises/drops 7\%. After the launch of the 'Circuit Breaker', it was activated twice in the first week. Because of complaints from investors, the Chinese government abandoned this mechanism on 8 January 2016.

In China, individual investors make up $82.24 \%$ of total trading volume in 2013 (Han and $\mathrm{Li}$ 2017), whereas institutional investors dominate in developed markets. Most individual investors focus on price changes and are less concerned with fundamental economic and firm-level information. The turnover rate in the Chinese stock market is much higher than that in developed markets, implying that a large proportion of trading activities are speculative rather considered as investments. Many individual investors are heavily influenced by market rumours. Individual investors tend to follow the news and purchase stocks in a herding manner (Tan et al. 2008), which makes the market highly volatile. 
There is a lack of risk management tools in the Chinese stock market. As a matter of fact, short-selling stocks in China are still limited and investors can mainly buy stocks. Index futures are supposed to be a suitable tool to hedge downside risk. However, the Chinese regulator imposed various restrictions on trading index futures in August 2015 because it suspected that some investors participated in 'malicious' short selling of index futures. Many private funds and security firms were under investigation for betting on a market drop. As a result, the trading volume of the index futures shrank substantially. For example, IF1509 had a trading volume of 2.42 million contracts on 25 August 2015, but it dropped to 3,810 on 7 September 2015. Utilising index futures to manage risk is still subject to a number of restrictions (e.g. no more than 10 contracts are allowed to open). Due to restrictions on domestic index futures markets, investors are not able to freely trade index futures. Many investors tend to trade Chinese index futures products in foreign markets, like the FTSE China A50 index futures on the Singapore Exchange and E-mini FTSE China 50 index futures on the Chicago Mercantile Exchange. This has caused an outflow of capital from China.

During 2015, it has been observed that fund-matching activities are very active. Fund matching refers to borrow funds from trust companies, structured mutual fund companies and other sources. Unlike margin loan and margin financing, the regulation on fund matching is much less strict, which can be an essential cause of the high leverage. For example, umbrella trusts are not required to register with the China Securities Depository and Clearing Corporation. Umbrella trusts contain two sorts of tranches. Banks purchase the senior/tranches, which guarantee fixed returns. Subordinate tranches are sold to private clients, like wealthy individuals, private companies and fund-matching companies, and provide uncertain returns depending on the performance of the wealth management product. In other words, subordinate tranches would get the rest of investment profits. Jiang (2014) claims that the Minsheng Bank, China Everbright Bank and China Merchants Bank were heavily involved in the business of umbrella trusts. There are no accurate data about the size of umbrella trusts but some estimations indicate that they accounted for roughly 200 billion RMB by the end of 2014 (Hsu 2015). In favour of high interest rates, fundmatching companies lend funds to investors by providing margin loans without sufficient consideration of risk. Yap (2015) points out that by 30 June 2015, fundmatching companies channelled 500 billion RMB from opening multiple and subdivided securities accounts with brokerages. These fund-matching companies were seldom regulated until CSRC imposed restrictions on them in July 2015.

\section{Methodology}

\section{Defining bear, sidewalk and bull markets}

In practice, investors tend to determine market conditions arbitrarily and different conclusions might be drawn for the same market in the same period. In the existing academic literature, the definition of market conditions varies considerably. In one of the early studies, Fabozzi and Francis (1977) propose three ways to define market conditions. The first way is to distinguish bull and bear markets (BB): it defines months when the market rises as in the bull market, but months when the market 
rises near the bearish periods are treated as part of the bear market. The second way defines up and down markets (UD): months in which return was non-negative are defined as up months, and months in which return was negative are defined as down months. And the third way is about substantial up and down months (SUD): months when the market moves up substantially, months when the market moves down substantially, and months when the market moves neither up substantially nor down substantially, but the threshold for a substantial move is arbitrarily defined.

In more recent studies, a loose definition by Chauvet and Potter (2000) proposes that market prices generally increase (decrease) in a bull (bear) market. Edwards and Caglayan (2001) simply define that bull market months are those in which the S\&P index rises by $1 \%$ or more, and bear market months are those in which the S\&P index falls by $1 \%$ or above. Lunde and Timmermann (2004) claim that a bull (bear) market starts when the market price increases (decreases) by a certain percentage, e.g. $20 \%$, from the previous local bottom (peak). Gonzalez et al. (2006) utilise two formal turning point methods to detect the timing of BB. Cheng, Lee, and Lin (2013) define bull (bear) markets as the periods with at least three consecutive months of positive (negative) returns.

It is necessary to propose our own definition of market conditions for three reasons. Firstly, there is no generally accepted definition of the market conditions. Secondly, the market conditions are mostly defined based on monthly data. Finally and most importantly, the current definitions are usually based on a dichotomy, i.e. the bull and the bear market (or the up and the down market). The only exception is the SUD in Fabozzi and Francis (1977), but their threshold for a substantial move is arbitrarily defined. In contrast, we systemically define the bear, sidewalk and bull market conditions from the perspective of distributional features.

\section{Definition bear market}

- The mean of the distribution of the daily returns conditional on the bear market should be less than 0 .

- It is expected that the frequency of negative returns is larger than that of positive returns.

- Due to the above distributional features, the market prices in the bear market are generally falling.

\section{Definition sidewalk market}

- The mean of the distribution of the daily returns conditional on the sidewalk market should be very close to 0 .

- It is expected that roughly an equal number of positive and negative returns are observed.

- Due to the above distributional features, market prices stay within a certain band and show a mean reversion pattern.

\section{Definition bull market}

- The mean of the distribution of the daily returns conditional on the bull market should be larger than 0 . 
- The frequency of positive returns is expected to be larger than that of negative returns.

- Due to the above distributional features, market prices in the bull market are generally rising. In straightforward notation, the mean in each market is as follows:

$$
\begin{aligned}
& \mu\left(S_{t}\right)=\mu_{1}<0, \text { if } \mathrm{S}_{t}=1 \text { ('bear' market) } \\
& \mu\left(S_{t}\right)=\mu_{2} \approx 0, \text { if } \mathrm{S}_{t}=2 \text { ('sidewalk' market) } \\
& \mu\left(S_{t}\right)=\mu_{3}>-0, \text { if } \mathrm{S}_{t}=3 \text { ('bull' market) }
\end{aligned}
$$

The variance of each market can be denoted as

$$
\begin{aligned}
& \sigma^{2}\left(S_{t}\right)=\sigma_{1}^{2}, \text { if } S_{t}=1 \text { ('bear' market) } \\
& \sigma^{2}\left(S_{t}\right)=\sigma_{2}^{2}, \text { if } S_{t}=2 \text { ('sidewalk' market) } \\
& \sigma^{2}\left(S_{t}\right)=\sigma_{3}^{2}, \text { if } S_{t}=3 \text { ('bull' market) }
\end{aligned}
$$

where we expect that the bear market should have the highest variance (i.e. $\sigma_{1}^{2}>\sigma_{2}^{2}$ and $\sigma_{1}^{2}>\sigma_{3}^{2}$ ) because it is normally the most volatile market.

\section{Hidden semi-Markov model}

The HSMM is an extension of the HMM by explicitly specifying the sojourn time (a.k.a. dwell time, occupancy time, duration time) distribution. The underlying state process is a semi-Markov chain. HSMM was originally introduced in the 1980s for speech recognition and now has a wide range of applications in the areas of, e.g. handwriting recognition, functional MRI brain mapping and network anomaly detection. Yu (2010) provides a comprehensive review of HSMM, including parameter estimation, model inference and applications.

HSMM is comprised of two processes, the unobservable state process, $s_{1}, s_{2}, \ldots, s_{T}$ and the observation process $x_{1}, x_{2}, \ldots, x_{T}$. Each state has a sequence of observation. The sojourn time is explicitly defined by the sojourn time distribution.

The component distribution that produces a sequence of observations with length $d$ starting at time $t+1$ is shown as:

$$
b_{i, d}\left(x_{t+1: t+d}\right)=\mathrm{P}\left(x_{t+1: t+d} \mid s_{[t+1: t+d]}=i\right)
$$

where $i$ is one of the states (i.e. $i \in\{1,2, \ldots, m\}$ ); $x_{t+1: t+d}$ stands for the sequence of observation from time $t+1$ to $t+d$; and $s_{[t+1: t+d]}$ represents the sequence of states starting at time $t+1$ and ending at $t+d$, inclusive. In other words, State $i$ that begins at $t+1$ produces a sequence of $d$ observations.

The state transition probability that State $i$ of length $d$ enters into State $j$ of length $d^{\prime}$ is defined in Equation (2):

$$
\gamma_{(i, d)\left(j, d^{\prime}\right)}=\mathrm{P}\left(s_{\left[t+1: t+d^{\prime}\right]}=j \mid s_{[t-d-1: t]}=i\right)
$$

where $i$ and $j$ belong to one of the states (i.e. $i, j \in\{1,2, \ldots, m\}$ ). After staying in State $i$ for sojourn time $d$, the next state has to go from State $i$ to other states. 
The transition from one state to the same state itself is 0 , i.e. $\gamma_{(i, d)\left(i, d^{\prime}\right)}=0$. Hence, the diagonal elements in the transition probability matrix (TPM) are zeros. The entries in TPM need to be associated with its sojourn time. The definition of TPM for HSMM is presented in Equation (3):

$$
\Gamma=\left(\begin{array}{cccc}
0 & \gamma_{\left(1, d_{1}\right)\left(2, d_{2}\right)} & \cdots & \gamma_{\left(1, d_{1}\right)\left(m, d_{m}\right)} \\
\gamma_{\left(2, d_{2}\right)\left(1, d_{1}\right)} & 0 & \cdots & \gamma_{\left(2, d_{2}\right)\left(m, d_{1 m}\right)} \\
\vdots & \vdots & \ddots & \vdots \\
\gamma_{\left(m, d_{m}\right)\left(1, d_{1}\right)} & \gamma_{\left(m, d_{m}\right)\left(2, d_{2}\right)} & \cdots & 0
\end{array}\right)
$$

The summation of the rows in TPM has to be 1 . The sojourn time is $d_{i}$, $i \in\{1,2, \ldots, m\}$, for each state follows its sojourn time distribution. The sojourn time distribution is defined in Equation (4):

$$
d_{i}(u)=P\left(s_{t+u+1} \neq j, s_{[t+1: t+u]}=j \mid s_{t+1}=j, s_{t} \neq j\right)
$$

Following Bulla and Bulla (2006), we adopt the right-censored type HSMM because the assumption of the classical HSMM that the last observation always coincides with the exit from a state does not seem to be realistic for financial time series data.

For our empirical study, we adopt the three-state HSMM with normal distributions as component distributions. The three states in the HSMM are expected to correspond to the bear, sidewalk and bull markets. The normal distribution is simple and fits our data well. The sojourn time distribution is set to be a logarithmic distribution because it only has one parameter and maintains the simplicity of the model. Estimations are carried out using the EM algorithm. The Viterbi algorithm is employed to globally decode the most likely sequence of states based on the data observed. Bulla, Bulla, and Nenadić (2010) provide a basis implementation of HSMM Q1 as an R package. Our implementation is based on their package.

\section{Empirical results \\ Data description}

We apply the three-state HSMM to analyse the daily returns of stock indexes in eight countries, including the CSI 300 (China), S\&P 500 (United States), FTSE 100 (United Kingdom), CAC 40 (France), DAX (Germany), Nikkei 225 (Japan), STI (Singapore) and ASX 200 (Australia). The sample period is from 8 April 2005 to 26 February 2016, slightly more than a decade. The reason for using this sample period is that the start date is when the CSI 300 was first launched. There are 2,645 observations for each index. The source of our data is Wind.

The daily return is defined as 100 times the first-order difference of the natural logarithm of the closing price series:

$$
r_{t}^{i}=100 \times\left(\ln \left(P_{t}^{i}\right)-\ln \left(P_{t-1}^{i}\right)\right)
$$

where $P_{t}^{i}$ is the daily closing price of the market index $i$ at time $t$. 
Table 1. Component distribution.

\begin{tabular}{|c|c|c|c|c|c|c|}
\hline & \multicolumn{2}{|c|}{ State 1 (Bear) } & \multicolumn{2}{|c|}{ State 2 (Sidewalk) } & \multicolumn{2}{|c|}{ State 3 (Bull) } \\
\hline & Mean & Variance & Mean & Variance & Mean & Variance \\
\hline CSI 300 & -0.513 & (9.719) & -0.020 & $(1.343)$ & 0.614 & $(2.058)$ \\
\hline S\&P 500 & -0.140 & (8.726) & -0.042 & (1.375) & 0.115 & $(0.244)$ \\
\hline FTSE 100 & -0.245 & $(9.346)$ & -0.018 & (1.427) & 0.082 & $(0.297)$ \\
\hline CAC 40 & -0.330 & (11.611) & -0.051 & (2.219) & 0.123 & $(0.526)$ \\
\hline DAX & -0.316 & (10.180) & -0.018 & (1.920) & 0.187 & $(0.393)$ \\
\hline Nikkei 225 & -0.382 & (16.169) & -0.056 & (2.311) & 0.156 & $(0.693)$ \\
\hline STI & -0.084 & $(8.831)$ & -0.053 & (1.644) & 0.061 & $(0.348)$ \\
\hline ASX 200 & -0.304 & $(6.680)$ & -0.040 & (1.449) & 0.098 & $(0.412)$ \\
\hline
\end{tabular}

\section{Component distribution: evidence of 'crazy bull'}

It is natural to interpret the three states in our HSMM as bear, sidewalk and bull according to our definition based on statistical features of return distributions. The estimated parameters of the component distribution in HSMM for all the countries under study are presented in Table 1 . The means of State 1 in all these countries are less than zero and their variances are the highest among the three states. The statistical features of State 1 are consistent with a bear market. It can be observed that the means in State 2 are all close to and slightly less than zero. The variance in State 2 is much lower than in State 1. The statistical features of State 2 meet our expectation of a sidewalk market, in which the return distribution should have a mean close to zero, enabling the price in the sidewalk market to fluctuate within a band. State 3 for all the countries have positive means, with the smallest variance among all of the states, except for the CSI 300 . The return distribution with positive mean and small variance allows the price in the bull market to increase steadily, which is an intrinsic feature of a bull market.

The first unique characteristic of the 'crazy bull' is the abnormally high variance in the Chinese bull market compared with other countries. The Chinese bull market has a variance of 2.058, almost three times higher than that of other countries. Japan has the second most unstable bull market with a variance of 0.693 . The bull markets in the United States and the United Kingdom are relatively more stable, as indicated by the small variances of 0.244 and 0.297 , respectively.

It is reasonable to expect that the variance is higher in the bear market for all the eight countries since the abrupt price fall during the market crash increases volatility. The bear markets in all the eight countries show similarly high variances. The variance in the Chinese bear market (9.719) is modest, between the highest variance in Japan (16.169) and the lowest in Australia (6.680). It seems that the volatility of the Chinese bear is normal.

There is no significant difference between the sidewalk markets of the eight countries. Interestingly, the means in the sidewalk markets are close to 0 but consistently slightly less than 0 . In Table 2, one-sample $t$-statistics show that none of the eight countries has a mean in State 2 which is significantly different from 0.

\section{Sojourn time: evidence of 'frequent and quick bear'}

Based on the global decoding results, Table 3 reports the number of days, number of times and average sojourn for the three market conditions in all the eight countries 
Table2. One-sample $t$-test.

\begin{tabular}{ll}
\hline$t$-Statistics of mean in State 2 & \\
\hline CSI 300 & -0.653 \\
S\&P 500 & -1.251 \\
FTSE 100 & -0.595 \\
CAC 40 & -1.316 \\
DAX & -0.533 \\
Nikkei 225 & -1.464 \\
STI & -1.270 \\
ASX 200 & -1.185 \\
\hline
\end{tabular}

Table 3. Days, times and average sojourn.

\begin{tabular}{|c|c|c|c|}
\hline & State 1 (Bear) & State 2 (Sidewalk) & State 3 (Bull) \\
\hline \multicolumn{4}{|l|}{ CSI 300} \\
\hline Number of days & 570 & 1,381 & \\
\hline Number of times & 22 & 6 & 25 \\
\hline Average sojourn & 25.91 & 230.17 & \\
\hline \multicolumn{4}{|l|}{ S\&P 500} \\
\hline Number of days & 269 & 1,242 & 1,133 \\
\hline Number of times & 3 & 30 & 27 \\
\hline Average sojourn & 89.67 & 41.40 & 41.96 \\
\hline \multicolumn{4}{|l|}{ FTSE 100} \\
\hline Number of days & 166 & 1,486 & 992 \\
\hline Number of times & 7 & 21 & 14 \\
\hline Average sojourn & 23.71 & 70.76 & 70.86 \\
\hline \multicolumn{4}{|l|}{ CAC 40} \\
\hline Number of days & 174 & 1,483 & 987 \\
\hline Number of times & 5 & 18 & 13 \\
\hline Average sojourn & 34.80 & 82.39 & 75.92 \\
\hline \multicolumn{4}{|l|}{ DAX } \\
\hline Number of days & 217 & 1,612 & 815 \\
\hline Number of times & 3 & 21 & 18 \\
\hline Average sojourn & 72.33 & 76.76 & 45.28 \\
\hline \multicolumn{4}{|l|}{ Nikkei 225} \\
\hline Number of days & 104 & 1,607 & 933 \\
\hline Number of times & 5 & 16 & 10 \\
\hline Average sojourn & 20.80 & 100.44 & 93.30 \\
\hline \multicolumn{4}{|l|}{ STI } \\
\hline Number of days & 213 & 938 & 1,493 \\
\hline Number of times & 4 & 16 & 12 \\
\hline Average sojourn & 53.25 & 58.63 & 124.42 \\
\hline ASX 200 & & & \\
\hline Number of days & 188 & 1,251 & 1,205 \\
\hline Number of times & 4 & 16 & 11 \\
\hline Average sojourn & 47.00 & 78.19 & 109.55 \\
\hline
\end{tabular}

during our sample period. Compared with developed markets, the Chinese stock market shows the characteristics of 'quick bull', 'frequent and quick bear' and 'long sidewalk'.

It should be highlighted that the average sojourn time of the bull market in China (27.72) is the shortest, while for developed markets it is more than 40 trading days. During our sample period, the Chinese market was in the bull market for 693 trading days, but entered and exited the bull market 25 times. We find that the United States is also in the bull market for a large number of times (27). However, the total number of days when the United States is in the bull market $(1,133)$ is nearly double that of China, which results in a relatively longer average sojourn in the bull market (41.96). 
Table 4. Transition probability matrix.

\begin{tabular}{|c|c|c|c|c|}
\hline & From/To & State 1 (Bear) & State 2 (Sidewalk) & State 3 (Bull) \\
\hline \multirow[t]{3}{*}{ CSI 300} & State 1 (Bear) & $0.00 \%$ & $0.04 \%$ & $99.96 \%$ \\
\hline & State 2 (Sidewalk) & $48.45 \%$ & $0.00 \%$ & $51.55 \%$ \\
\hline & State 3 (Bull) & $77.05 \%$ & $22.95 \%$ & $0.00 \%$ \\
\hline \multirow[t]{3}{*}{ S\&P 500} & State 1 (Bear) & $0.00 \%$ & $99.90 \%$ & $0.10 \%$ \\
\hline & State 2 (Sidewalk) & $5.18 \%$ & $0.00 \%$ & $94.82 \%$ \\
\hline & State 3 (Bull) & $0.00 \%$ & $100.00 \%$ & $0.00 \%$ \\
\hline \multirow[t]{3}{*}{ FTSE 100} & State 1 (Bear) & $0.00 \%$ & $100.00 \%$ & $0.00 \%$ \\
\hline & State 2 (Sidewalk) & $14.61 \%$ & $0.00 \%$ & $85.39 \%$ \\
\hline & State 3 (Bull) & $0.00 \%$ & $100.00 \%$ & $0.00 \%$ \\
\hline \multirow[t]{3}{*}{ CAC 40} & State 1 (Bear) & $0.00 \%$ & $100.00 \%$ & $0.00 \%$ \\
\hline & State 2 (Sidewalk) & $13.10 \%$ & $0.00 \%$ & $86.90 \%$ \\
\hline & State 3 (Bull) & $0.00 \%$ & $100.00 \%$ & $0.00 \%$ \\
\hline \multirow[t]{3}{*}{ DAX } & State 1 (Bear) & $0.00 \%$ & $99.93 \%$ & $0.07 \%$ \\
\hline & State 2 (Sidewalk) & $7.81 \%$ & $0.00 \%$ & $92.19 \%$ \\
\hline & State 3 (Bull) & $0.00 \%$ & $100.00 \%$ & $0.00 \%$ \\
\hline \multirow[t]{3}{*}{ Nikkei 225} & State 1 (Bear) & $0.00 \%$ & $100.00 \%$ & $0.00 \%$ \\
\hline & State 2 (Sidewalk) & $20.33 \%$ & $0.00 \%$ & \\
\hline & State 3 (Bull) & $0.00 \%$ & $100.00 \%$ & $0.00 \%$ \\
\hline \multirow[t]{3}{*}{ STI } & State 1 (Bear) & $0.00 \%$ & $100.00 \%$ & $0.00 \%$ \\
\hline & State 2 (Sidewalk) & $17.89 \%$ & $0.00 \%$ & $82.11 \%$ \\
\hline & State 3 (Bull) & $0.00 \%$ & & $0.00 \%$ \\
\hline \multirow[t]{3}{*}{ ASX 200} & State 1 (Bear) & $0.00 \%$ & & $0.00 \%$ \\
\hline & State 2 (Sidewalk) & $16.88 \%$ & $0.00 \%$ & $83.12 \%$ \\
\hline & State 3 (Bull) & $0.00 \%$ & $100.00 \%$ & $0.00 \%$ \\
\hline
\end{tabular}

China along with the United Kingdom and Japan are found to have a short average sojourn in the bear market, while the other five countries have more than 30 trading days. It should be pointed out that China was in the bear market 22 times, while all of the other countries were in the bear market around five times in our sample period. We can argue that the 'quick bear' happens in the United Kingdom and Japan but not frequently, while China has a 'frequent and quick bear'.

The average sojourn of the sidewalk market in China is 230.17 , more than twice that of other countries. In addition, China was in the sidewalk market only six times in the sample period. Every time China entered the sidewalk market, the long-term trend in the stock market cannot be established unless the long sojourn in the sidewalk market has elapsed. The most obvious sidewalk period in China is from 2011 to 2014, where the CSI 300 stayed roughly between 2,000 and 3,000. During that period, whenever the CSI 300 was near the ceiling or floor, it would eventually return to the band again.

\section{Transition probability matrix: evidence of 'no buffer zone'}

We find a very unique characteristic, the 'no buffer zone', of the Chinese stock market from the estimated TPM in Table 4. The direct transition probability from the bear market to bull market (or the opposite direction) is close to $0 \%$ in all developed markets. It is clearly shown that all developed markets always have the sidewalk market as a buffer zone between the bull and the bear market. Nevertheless, the TPM in China is very special with a particularly high-transition probability from the bear market to the bull market (nearly 100\%) and a relatively high-transition probability from the bull market to the bear market (77.05\%). The buffer zone effect was not found to exist in China over the sample period. The direct transition between the bull 
market and the bear market is typical. It is found that the bull market and the bear market are mixed together many times in the Chinese stock market.

The second difference between the TPM of China and other countries is that in China the transition probability from sidewalk market to the other two markets is roughly 50\%, while other developed markets tend to have a much larger probability to be a bull maket after exiting the sidewalk market. The developed market normally has a probability of less than $20 \%$ for exiting the sidewalk market to the bear market. Though this might be due to the short sample period of our data, this is what actually happened in the last decade, including the four stages of the economic and business cycle, namely economic prosperity before 2007 , the financial crisis in 2008 , financial depression since 2009 and economic rebound after 2010.

\section{Discussion and policy implications}

Through the comparison with international markets, we find many unique characteristics of the Chinese stock market. The most prominent three characteristics are 'crazy bull', 'frequent and quick bear' and 'no buffer zone'. All of these characteristics indicate that the Chinese stock market is much more volatile than other developed markets. These three characteristics are of great importance for policymakers. In order to build a more reliable and stable stock market, we would like to discuss the possible causes of the unique characteristics and policy implications from our findings.

\section{'Crazy bull' - rational security analysis and investor structure adjustment}

Compared with developed markets, the Chinese stock market has considerably high variance in the bull market, which may be induced by the herding behaviour of individual investors. Kim and Wei (2002) provide evidence that individual investors are more likely to engage in herding. Kumar and Lee (2006) use more than 1.85 million individual investor transactions at a major US discount brokerage house to show that individual investors buy or sell stocks in concert during 1991-1996. Moreover, individual investors can be easily influenced by news and market sentiment. Barber and Odean (2007) test and confirm that individual investors are net buyers of 'attentiongrabbing stocks'.

In order to mitigate the herding behaviour, Lao and Singh (2011) suggest that large financial institutions can bring more rational security analysis to the general public, which can decrease speculative investments by individual investors. Most individual investors have little knowledge of stock markets and focus on short-term price changes, rather than the fundamental values of listed companies. It is imperative to guide individual investors to focus on the fundamental values of firms and make rational investments.

In China, individual investors account for $82.24 \%$ of the total trading volume in 2013 (Han and Li 2017), whereas institutional investors dominate in developed markets. Boehmer and Kelley (2009) show that stocks with greater institutional ownership are priced more efficiently. The Chinese government needs to adjust investor structure and promote the development of institutional investors, such as asset management firms, private funds and mutual funds. Institutional investors have expert 
knowledge and skills to manage professional investments that seek long-term returns under proper risk management.

\section{'Frequent and quick bear' - risk management tools}

In China, the bear market has a short sojourn time and occurs very frequently. As a matter of fact, short selling is limited in the Chinese stock market. Most investors can only buy stocks in China. Mei, Scheinkman, and Xiong (2009) point out that mispricing can hardly be arbitraged at both the market level and the individual stock level in a market with stringent constraints on short selling. It is very difficult to hedge downside risk during the bear market.

Q2 Index futures are appropriate tools to hedge downside risk during a bear market. Lien and Tse (2000) utilise futures contracts to develop a hedge strategy that minimises the lower partial moments. Lien and Tse (2002) review the theoretical background and econometric implementation of various futures hedging. Chen, Lee, and Shrestha (2003) investigate different theoretical methods to find optimal futures hedge ratios.

Although the China Financial Futures Exchange launched the first index futures product, the CSI 300 index futures, on 16 April 2010, the trading of index futures is under strict restrictions. Firstly, there are high barriers for individual investors to participate because of the high deposit requirement and the minimum account size requirement. Secondly, the margin requirement is $15-18 \%$, much higher than that of index futures in developed countries. Thirdly, qualified foreign institutional investors are not eligible to trade index futures.

In July 2015, more restrictions on index futures trading were enforced which have hampered the development of financial markets. The strictest rule is that the number of opening contracts cannot exceed 10 per day. As a result, investors can hardly use the index futures as a tool to manage risk. In order to develop the Chinese stock market, it is crucial to remove restrictions on the trading of domestic index futures products for investors to hedge the downside risk during frequent bear markets. In this way, the Chinese stock market can stay on the promised path of reform to become more market-oriented rather than policy-oriented.

\section{'No buffer zone' - restriction on leverage}

The most notable characteristic of the Chinese stock market is that the bull market is typically mixed with the bear market and that there is no sidewalk market between them. In developed markets, the sidewalk market always functions as the 'buffer zone' between the bear market and the bull market. The 'no buffer zone' phenomenon can be explained by the overreaction effect in behavioural finance. Bondt and Thaler (1985) find that most investors usually overreact to unexpected and dramatic news, suggesting the existence of weak-form market inefficiencies. Wang and $\mathrm{Yu}$ (2004) examine the overreaction effect in China during the period from 1994 to 2000 and find that overreaction is most pronounced in the A-share market.

More importantly, Hsu (2015) points out that the excess leverage from fund matching exaggerates the overreaction effect in China. In 2015, the Chinese stock 
market encountered a frenzied bull and then a dismal bear, which increased volatility to a historically high level. It is highly likely that the abnormally high volatility was caused by excess leverage, specifically through fund matching, like umbrella trusts and fund-matching companies. By margin loan and margin financing, brokerages can increase funding by up to twice the margin (i.e. ratio at 1:2). Through umbrella trusts, one may leverage up to five times the margin (i.e. ratio at 1:5).

The excess leverage of fund matching exaggerates the downside risk of the Chinese stock market, which caused the contagion of the market crisis. It is inevitable that detailed regulation needs to be imposed on umbrella trusts and fund-matching companies. There should be strict rules in the banking sector to provide funding for umbrella trusts. Leverage should be capped at a much lower level. The monitoring of fund-matching companies needs to be significantly reinforced. Finally, information on fund matching should be more transparent to the public.

\section{Conclusion}

In this paper, we first review the special features of the Chinese stock market and then a three-state HSMM is employed to decode its market conditions and those of seven developed markets. Comparing the estimation and global decoding results, we find three unique characteristics of the Chinese stock market, namely 'crazy bull', 'frequent and quick bear' and 'no buffer zone'. 'Crazy bull' refers to the fact that the variance of the bull market in the Chinese stock market is noticeably higher than that of developed markets. 'Frequent and quick bear' is implied by the fact that the bull market occurs frequently in China and the sojourn time of the Chinese bull market is short. 'No buffer zone' is the most prominent characteristic. It is observed that the sidewalk in developed markets always functions as a buffer zone between the bear and bull markets, while this never occurs in China.

Our findings are meaningful for investors and policymakers at two levels. Firstly, at the microlevel, investors have more in-depth understanding of the Chinese stock market, which has several prominent differences from developed markets. In China, the bull market is more volatile, the bear market happens more frequently, and the sidewalk market does not function as a buffer zone. All of these characteristics suggest that investors need to carefully manage the risk of their investment and avoid speculation. Secondly, at the macrolevel, it is very important for the Chinese government to adjust the investor structure, to provide risk management tools and to strengthen supervision on the excess leverage from fund matching. However, the limitation of this paper is that our sample period is not long enough and daily returns may contain noise. Moreover, other frequencies of return could be used to conduct robustness checking. Further work could be done based on an abnormal return, rather than the original raw daily returns.

\section{Acknowledgements}

The authors appreciate the constructive comments and suggestions from the anonymous referees. 


\section{Disclosure statement}

No potential conflict of interest was reported by the authors.

\section{Funding}

The research of Shixuan Wang was supported by the Economic and Social Research Council (UK) [grant number ES/J50001X/1].

\section{References}

Barber, B. M., and T. Odean. 2007. "All that Glitters: The Effect of Attention and News on the Buying Behavior of Individual and Institutional Investors." The Review of Financial Studies 21: 785-818.

Boehmer, E., and E. K. Kelley. 2009. "Institutional Investors and the Informational Efficiency of Prices." The Review of Financial Studies 22: 3563-3594.

Bondt, W. F. M., and R. Thaler. 1985. "Does the Stock Market Oyerreact?" The Journal of Finance 40: 793-805.

Bulla, J., and I. Bulla. 2006. "Stylized Facts of Financial Time Series and Hidden Semi-Markov Models." Computational Statistics and Data Analysis 51: 2192-2209.

Bulla, J., I. Bulla, and O. Nenadić. 2010. "HSMM: An R Package for Analyzing Hidden SemiMarkov Models." Computational Statistics and Data Analysis 54: 611-619.

Chauvet, M., and S. Potter. 2000. "Coincident and Leading Indicators of the Stock Market." Journal of Empirical Finance 7: 87-111.

Chen, S.-S., C-f. Lee, and K. Shrestha. 2003. “Futures Hedge Ratios: A Review.” The Quarterly Review of Economics and Finance 43: 433-465.

Cheng, T. Y., C. I. Lee, and C. H. Lin. 2013. "An Examination of the Relationship between the Disposition Effect and Gender, Age, the Traded Security, and Bull-Bear Market Conditions." Journal of Empirical Finance 21: 195-213.

Edwards, F. R., and M. O. Caglayan. 2001. "Hedge Fund and Commodity Fund Investments in Bull and Bear Markets." The Journal of Portfolio Management 27: 97-108.

Fabozzi, F. J., and J. C. Francis. 1977. "Stability Tests for Alphas and Betas over Bull and Bear Market Conditions." The Journal of Finance 32: 1093-1099.

Girardin, E., and Z. Liu. 2003. "The Chinese Stock Market: A Casino with 'Buffer Zones?"Journal of Chinese Economic and Business Studies 1: 57-70.

Gonzalez, L.,P., Hoang, J. G. Powell, and S. Jing. 2006. "Defining and Dating Bull and Bear Markets: Two Centuries of Evidence.” Multinational Finance Journal 10: 81-116.

Han, X., and Y. Li. 2017. "Can Investor Sentiment Be a Momentum Time-series Predictor? Evidence from China." Journal of Empirical Finance 42: 212-239.

Hsu, S. 2015. "China's Volatile Stock Market and Its Implications." University of Nottingham, China Policy Institute Policy Paper 2015: No. 7.

Jiang, F. 2014. "Bull Leverage Funds." Caixin Weekly, December 5.

Kim, W., and S.-J. Wei. 2002. "Foreign Portfolio Investors Before and During a Crisis." Journal of International Economics 56: 77-96.

Kumar, A., and C. Lee. 2006. "Retail Investor Sentiment and Return Comovements." The Journal of Finance 61: 2451-2486.

Lao, P., and H. Singh. 2011. "Herding Behaviour in the Chinese and Indian Stock Markets." Journal of Asian Economics 22: 495-506.

Lien, D., and Y. K. Tse. 2000. "Hedging Downside Risk with Futures Contracts." Applied Financial Economics 10: 163-170.

Lien, D., and Y. K. Tse. 2002. "Some Recent Developments in Futures Hedging." Journal of Economic Surveys 16: 357-396.

Liu, Z., and S. Wang. 2017. "Decoding Chinese Stock Market Return: Three-state Hidden Semi-Markov Model.” Pacific-Basin Finance Journal 44: 127-149. 
Lunde, A., and A. Timmermann. 2004. "Duration Dependence in Stock Prices." Journal of Business \& Economic Statistics 7: 87-111.

Mei, J., J. Scheinkman, and W. Xiong. 2009. "Speculative Trading and Stock Prices: Evidence from Chinese AB Share Premia." Annals of Economics and Finance 10: 225-255.

$\mathrm{Ni}, \mathrm{Z}$.-X., D.-Z. Wang, and W.-J. Xue. 2015. "Investor Sentiment and Its Nonlinear Effect On Stock Returns - New Evidence from the Chinese Stock Market Based on Panel Quantile Regression Model." Economic Modelling 50: 266-274.

Nielsen, S., and J. O. Olesen. 2001. "Regime-switching Stock Returns and Mean Reversion." Copenhagen Business School Working Paper No. 11-2000.

Rydén, T., T. Teräsvirta, and S. Åsbrink. 1998. "Stylized Facts of Daily Return Series and the Hidden Markov Model." Journal of Applied Econometrics 13: 217-244.

Schaller, H., and S. Van Norden. 1997. "Regime Switching in Stock Market Returns." Applied Financial Economics 7: 177-191.

Tan, L., T. C. Chiang, J. R. Mason, and E. Nelling. 2008. "Herding Behavior in Chinese Stock Markets: An Examination of A and B Shares." Pacific-Basin Finance Journal 16: 61-77.

Viterbi, A. J. 1967. "Error Bounds for Convolutional Codes and an Asymptotically Optimum Decoding Algorithm." IEEE Transactions on Information Theory 13: 260-269.

Wang, C., and M. Yu. 2004. "Trading Activity and Price Reversals in Futures Markets." Journal of Banking and Finance 28: 1337-1361.

Yap, C.-W. 2015. "China Crackdown on Margin Lending Hits Peer-to-Peer Lenders." Dow Jones News, July 13.

Yu, S.-Z. 2010. "Hidden Semi-Markov Models." Artificial Intelligence 174: 215-243. 